\title{
Notas sobre María de Portugal, reina de Castilla, como señora de Guadalajara $(1328-1356)^{*}$
}

\author{
Notes on María of Portugal, Queen of Castile, as Lady of \\ Guadalajara (1328-1356)
}

\author{
Pablo Martín Prieto** \\ RESUMEN ABSTRACT
}

El presente trabajo se centra en una importante figura de la historia de Castilla en el siglo XIV, la reina castellana María de Portugal, consorte de Alfonso XI y madre de Pedro I, como señora de la entonces villa de Guadalajara. El análisis de cierta serie de ordenanzas concejiles formadas bajo su autoridad como señora de la villa sirve de punto de partida para establecer su actuación al frente del señorío de dicha población, por lo demás corroborado por algunos otros documentos a los que también se pasa revista. La presencia de María de Portugal como señora de Guadalajara ayuda asimismo a una mejor comprensión del arraigo en dicha localidad de la familia de los Pecha, dos de cuyos miembros más eminentes estuvieron ligados al servicio de la reina.

\section{PALABRAS CLAVE}

María de Portugal, Alfonso XI, Pedro I, Castilla, Guadalajara.
This study focuses on a relevant figure in the history of Castile in the fourteenth century, the Castilian queen Maria of Portugal -wife of Alfonso XI and mother of Pedro I- as lady of the town of Guadalajara. The study of a set of council ordinances approved under her authority is the first step to determine her role as lady of this domain which is corroborated by other records discussed in this article. The presence of Maria of Portugal as lady in Guadalajara also allows a better understanding of the position of the Pecha family within the town, two of whose members were part of the queen's innercircle.

\section{KEY WORDS}

Maria of Portugal, Alfonso XI, Pedro I, Castile, Guadalajara.

\section{EL TEMA}

Entre quienes se han ocupado y se ocupan de la historia de Guadalajara en los tiempos medievales, ha pasado casi inadvertida la figura de la reina doña María de

* Fecha de recepción del artículo: 2010-11-3. Fecha de aceptación del artículo: 2011-1-26.

** Universidad Complutense de Madrid. C.e.: pablomartinprieto@ghis.ucm.es 
Portugal, consorte de Alfonso XI, quien ostentó y —lo que parece más relevantenos consta que ejerció durante unas décadas el señorío de la entonces villa. Sin duda, el tema de las reinas e infantas de Castilla que desde su reconquista ostentaron el señorío de Guadalajara constituye uno de los más sugestivos cauces de aproximación a los lazos de la población con la corona, y esta razón aporta un ingrediente adicional de interés a la labor de establecer con precisión la nómina de estas damas de la realeza castellana que mantuvieron una especialísima relación, más o menos estrecha o frecuente, pero sin duda de la máxima relevancia institucional, con la Guadalajara de la época.

Tradicionalmente, los eruditos locales e historiadores que se han ocupado del tema han destacado el papel y la figura de algunos miembros femeninos de la familia real castellana, reinas consortes e infantas, que en tiempos medievales figuraron como señoras de Guadalajara; por lo general, la actuación de estas damas durante los periodos en que se hallaron al frente del señorío se describe de manera fragmentaria y anecdótica, haciendo mención de disposiciones tomadas en uso de sus prerrogativas, o bien de gracias y mercedes que el concejo o algunos conventos de la villa alcanzaron por la benevolencia o intercesión de estas influyentes señoras. Sin embargo, creemos que elaborar la nómina entera de quienes en tiempos medievales ostentaron el señorío de Guadalajara, así como estudiar los pormenores de su gestión al frente del mismo constituye todavía un trabajo pendiente, al que las presentes páginas tan sólo pretenden realizar una modesta aportación de índole parcial.

\section{LAS ORDENANZAS «DE CUANDO GUADALAJARA ERA DE UNA REINA»}

Sin duda, el documento más importante en orden a ilustrar las relaciones de la reina María de Portugal con la que fuera villa de su señorío es un notable conjunto de ordenanzas municipales, regulando una amplia variedad de asuntos que atañen a la vida local, redactadas por iniciativa de ciertos funcionarios enviados a la villa por la reina para "corregir los fechos de la tierra», como entonces se dijo, de acuerdo con los oficiales competentes designados por el concejo para efectuar esta labor. Bien que conocidas de antiguo por una copia de hacia mediados del siglo XVI conservada en el Archivo Municipal de Guadalajara ${ }^{1}$, y publicadas en más de una ocasión ${ }^{2}$, cierta confusión tradicional en la datación de estas ordenanzas — perpetuada al parecer por la autoridad de Francisco Layna Serrano-, ha impedido asignarlas a su más adecuado contexto histórico y, en consecuencia, al-

\footnotetext{
1 Archivo Municipal de Guadalajara (en adelante, AMGU), Libro copiador de ordenanzas, doc. no. 133096.

2 LAYNA SERRANO, Francisco, Historia de Guadalajara y sus Mendozas en los siglos XV y XVI, Madrid, 1942, t. II, pp. 499-518.
} 
Notas sobre María de Portugal, reina de Castilla, como señora de Guadalajara...

canzar acerca de las mismas la interpretación más ajustada a las circunstancias concretas en las que vieron la luz.

En efecto, estas ordenanzas, que en la copia del archivo concejil guadalajareño se atribuyen, mediante un título poco concreto, a cierta época en que «la villa hera de una Reyna», fueron relacionadas por Layna con la reina Juana Manuel, consorte del primer Trastámara: para ello, el cronista provincial necesitó suponer que un error en la transmisión de la data había puesto la palabra era donde debía decir año, de manera que, por ejemplo, la expresión «era de mill e trezientos e setenta e nueve annos» debía interpretarse como referida, no al año de 1341, según el cómputo de la era hispánica, sino al año de 1379, contado desde el nacimiento de Cristo - y así, análogamente, con las restantes expresiones de datación que figuran en el documento ${ }^{3}$. De acuerdo con esta teoría, las ordenanzas habrían de estar fechadas entre 1379 y 1384, ámbito cronológico que, por demás, podría comportar alguna dificultad de interpretación con relación a la figura de la reina Juana Manuel, teniendo en cuenta que el extremo más reciente de este periodo se adentra ya en el reinado de Juan $\mathrm{I}^{4}$.

Siguiendo a Layna sin examinar de nuevo la cuestión, otros autores persistieron en la atribución de este importante conjunto de ordenanzas locales a la época de la reina Juana Manuel. No es éste el caso de José Miguel López Villalba, quien en su tesis doctoral corrigió con acierto la datación debida a Layna ${ }^{5}$. Por supuesto, aunque esta datación errónea de un documento en que el uso de la palabra era resulta perfectamente consistente y claro procedía a todas luces de un apriorismo sobre quién debía ser, de acuerdo con el criterio del célebre cronista, aquella reina y señora de Guadalajara a la que se refería el texto, lo cierto es que la datación preferida por Layna era, como tal, posible (pues la hipótesis de un error de copia no era, en sí misma, absurda —aunque sí infundada). Sin embargo, la consulta de otro ejemplar de las mismas ordenanzas, conservado en un importante manuscrito de la Real Biblioteca del Monasterio de San Lorenzo de El Escorial ${ }^{6}$, en cuyo texto figura también el término era en vez de año cada vez que se consigna la

${ }^{3}$ Así, en su edición, LAYNA aclara, en nota al pie de esta primera data: «Sin duda hay error de copia; donde dice Era, debe decir Año»: Op. Cit., t. II, p. 499; análogamente transcribe, páginas adelante: "en yllescas veynte e doss dias de diciembre era de myll e tresientos e ochenta e quatro años», para inmediatamente apostillar, en nueva nota al pie: «Error de copia; no se refiere a la Era, sino al año»: Idem, p. 514. El proceder de LAYNA en esta cuestión se apoya en la autoridad de Manuel PÉREZ VILLAMIL, quien se refiere brevemente a estas mismas ordenanzas como si fueran de 1379 en sus Aumentos a las Relaciones topográficas de España. Relaciones de pueblos que pertenecen hoy a la provincia de Guadalajara: Memorial Histórico Español, t. 46, Madrid, 1914, p. 66.

${ }^{4}$ LAYNA resuelve la cuestión afirmando que, de estas ordenanzas, los actos fechados en 1379 se adscriben al señorío de Juana Manuel, y los de 1384 a Beatriz de Portugal, consorte de Juan I: cfr. Op. Cit., t. II, p. 340.

5 LÓPEZ VILLALBA, José Miguel, Diplomática municipal medieval de Guadalajara, Tesis Doctoral leída en la Facultad de Geografía e Historia de la UNED, en 1995 (publicada en CD-Rom: Guadalajara, 2006), p. 30, nota 115. El mismo autor edita el texto del AMGU en las pp. 226-248.

6 Real Biblioteca del Monasterio de San Lorenzo de El Escorial, ms. X-II-19, «Ordenamientos y leyes de los reyes Enrique II, Juan I, Alonso XI, Enrique III, Juan II y Enrique IV; y Fuero y Ordenanzas de Guadalajara», fols. 120v-136v. 
datación, permitió a López Villalba descartar, por improbable, la antigua suposición de Layna sobre un eventual error de copia. La copia de El Escorial data, casi seguramente, de la segunda mitad del siglo XV; que en ella existiera el mismo error (era por año) que Layna creía descubrir en el manuscrito del archivo concejil de Guadalajara es, nuevamente, posible, pero altamente improbable y, en definitiva, se antoja poco verosímil.

Así pues, la opción de López Villalba le conducía a establecer correctamente la datación de estas ordenanzas, y de esta manera vino a afirmar (sin aportar mayores pruebas) el señorío de la reina María de Portugal sobre la villa de Guadalajara. Pero en último término, esta apuesta descansaba únicamente en la extremada improbabilidad de que un mismo error de copia se hubiera cometido tantas cuantas veces aparecía la datación de las ordenanzas, en ambos manuscritos disponibles de las mismas.

En nuestra opinión, lo que resta, alcanzado este punto, es apuntalar sin dejar resquicio a la duda la atribución de las ordenanzas a las fechas de 1341 y 1346 , y para lograr este objetivo es necesario proseguir las labores de análisis del texto, procediendo a identificar a algunos personajes que en él intervienen, y que inequívocamente se corresponden con esa época, dándose la circunstancia de que en algunos casos se relacionan directamente con el servicio de la reina María de Portugal ${ }^{7}$.

\section{LOS «CORREGIDORES» DE LA REINA MARÍA}

Aunque en las ordenanzas no se los identifica explícitamente con este título, sino con el de «jurados» y «alcaldes», el hecho de que acudieran a Guadalajara provistos con la misión de, textualmente, "corregir los fechos de la tierra", nos autoriza a referirnos a estos funcionarios de la corona con el nombre que les damos en el título de este apartado ${ }^{\text {. }}$.

El 23 de mayo de 1341 se presentaron ante el concejo de Guadalajara ciertos «jurados» comisionados por la señora de la villa, la reina, cuya carta portaban en esta razón: dichos funcionarios enviados por doña María eran «Domingo Juan de

7 En un estudio anterior, Caroline MIGNOT se refirió a estas ordenanzas, correctamente, como de 1341 y 1346, pero como de pasada, sin abordar específicamente el asunto de su datación, y citando siempre su texto por la edición de la obra de Layna, que en todo momento maneja, sin que parezca que esta autora llegase a tener conocimiento del otro manuscrito de estas ordenanzas conservado en El Escorial: "Le municipio de Guadalajara au XVème siècle, système administratif et économique (13411567)», Anuario de Estudios Medievales, 14, (1984), pp. 581-609.

8 Dejando a un lado posibles controversias terminológicas, es conocido el importante momento que el reinado de Alfonso XI representa en el proceso de introducción de estos «jueces de salario» o «Corregidores» en el ámbito municipal castellano: cfr., por ejemplo, BERMÚDEZ AZNAR, Agustín, El corregidor en Castilla durante la Baja Edad Media (1348-1474), Murcia, 1974. 
Notas sobre María de Portugal, reina de Castilla, como señora de Guadalajara...

Santo Tome, vezino de Salamanca», y «Juan Martinez»"9. El primero de estos jurados puede haber sido el alcalde de corte Domingo Juan de Salamanca, funcionario especializado en gestiones administrativas y habitual emisario regio cuya actuación al servicio del rey Pedro se documenta con cierta frecuencia al cabo de unos años ${ }^{10}$. El segundo, Juan Martínez, podría identificarse tentativamente con cierto miembro de la cámara real bajo el rey don Pedro y notario mayor de sus privilegios rodados, cuya actuación notarial en el reino de Toledo está acreditada en el mismo reinado ${ }^{11}$. Más allá de estas identificaciones probables, lo cierto es que ambos jurados colaboraron con el concejo de Guadalajara en la elaboración de una larga serie de ordenanzas locales.

Más tarde, en diciembre de 1346, dos nuevos personeros vinculados estrechamente al servicio de doña María acudieron a Guadalajara y, en colaboración con los funcionarios del concejo, acordaron e hicieron aprobar una nueva serie de ordenanzas, completando las anteriores. Estos dos nuevos emisarios o corregidores eran «Tel Fernandez de Toledo, alcalde mayor de la Reyna, e Garçia Alonso Triguero de Toro, alcalde de la dicha sennora de las alçadas de casa de la dicha sennora; e alcaldes por la dicha sennora Reyna en todas las sus villas e logares de aquende Duero» ${ }^{12}$. Se trata, a todas luces, de dos de los funcionarios más cualifi-

9 «En veynte e tres dias de mayo, era de mill e trezientos e setenta e nueve annos, vinieron a Guadalajara Domingo Juan de Santo Tome, vezino de Salamanca; e Juan Martinez, jurados, por corregir los fechos de la tierra, con carta de la Reyna; e entre todas otras cosas, fizieron hordenamiento commo pase en la tierra, commo adelante dira»: El Escorial, ms. X-II-19, fol. 120v.

10 Un Domingo Juan figura con alguna frecuencia como confirmante de los documentos expedidos por la cancillería de Alfonso XI entre 1335 y 1337: cfr. Colección de documentos para la Historia del Reino de Murcia. VI. Documentos de Alfonso XI (ed. Francisco de Asís VEAS ARTESEROS), Murcia, 1997: 1335, marzo 11, León (doc. CCXCI, p. 335); 1337, junio 18, Sevilla (doc. CCCXLIV, p. 388); 1337, julio 19, Sevilla (doc. CCCXLV, p. 389); 1337, diciembre 20, Mérida (docs. CCCXLVIII, p. 393; CCCXLIX, p. 394; CCCL, p. 395 y CCCLIV, p. 399). Domingo Juan de Salamanca fue enviado como juez real a Trujillo antes del 30 de abril de 1353: cfr. DÍAZ MARTíN, Luis Vicente, Colección diplomática de Pedro I de Castilla 1350-1369, Salamanca, 1997, doc. no. 815, t. III, p. 142 («Domingo lohan, mio alcalle en la mi corte»), comisionado el 11 de marzo de 1356 para fallar un pleito entre Cuéllar y Fuentepelayo («Domingo Juan, mi alcallde en la mi corte», idem, doc. no. 979, t. III, p. 290), y nuevamente medió en una disputa por los oficios concejiles en Trujillo en 1357 (Idem, doc. no. 1014, t. III, p. 316). Si ambos personajes, el que confirmaba documentos de la cancillería de Alfonso XI y el que ejecutó misiones para la administración del rey Pedro, son uno y el mismo, no puede, con todo y ser verosímil, precisarse sin sombra de ambigüedad.

11 Así consta su figura como miembro de la Cámara del Rey y su notario mayor de los privilegios rodados, amén de notario mayor del reino de Toledo, en: SALAZAR Y MENDOZA, Luis de, Origen de las dignidades seglares en Castilla y León, Madrid, 1794, p. 112.

12 «En Guadalajara, primero dia de dizienbre, era de mill e trezientos e ochenta e quatro annos, Tel Ferrandez de Toledo, alcalde mayor de la Reyna; e Garçia Alonso Triguero de Toro, alcalde de la dicha sennora de las alçadas de casa de la dicha sennora; e alcaldes por la dicha sennora Reyna en todas las sus villas e logares de aquende Duero; e estando en las casas de don Abrahen [tachado: «arrendador»] [al margen, en otra mano: «Alfandar»], do posa el dicho Tel Ferrandez, alcalde, e estando y Garçia Pardo Gallego; e Alvar Paez [anotación marginal, en otra mano: «Alvar Paez»]; e Diego Ferrandez; e Alonso Perez Pecha [anotación marginal, en otra mano: «Pecha»]; e Alvar Ruyz; e Ruy Perez; e Estevan Ferrandez; e Diego Ferrandez; e Diego Perez, recuero; que son de los doze omes buenos que han de ver fazienda del conçejo deste dicho logar Guadalajara; e Benito Perez, alcalde; e Juan Martinez de Ribafecha, escrivano de la Reyna; e Gonçalo [tachado: «e g»] Nunnez, fijo de Ferrand Gomez de Cordova; e Ruy Ferrandez, fijo de Nunno Ferrandez; otrosy, Juan Perez, ortelano; e Pascual Perez, yerno de donna Sancha; e Yuste Perez de Pennalver; e Ruy Garçia, carniçero; e Juan Martinez, avarquero; que son 
cados del equipo que se encargaba de gestionar los intereses señoriales de doña María, miembros de su «casa»: nada menos que su alcalde mayor y su alcalde de alzadas, encargados de la administración de los intereses de la reina en la vasta región de Castilla situada al sur del Duero.

Concretamente, es conocido el papel que Tel Fernández desempeñó al servicio directo de la reina María de Portugal, de la que sin duda fue hombre de confianza, como se atestigua por la circunstancia de haber sido nombrado por ella albacea en su testamento de 1351, donde la reina se refiere a él como su camarero mayor $^{13}$. De este Tel Fernández nos consta, asimismo, que estaba arraigado en Toledo, donde en época del rey Pedro llegaría a ostentar el oficio de alcalde mayor, realizando allí diversas gestiones de relieve al servicio del monarca que acreditan su protagonismo al frente de la administración regia en la ciudad del Tajo ${ }^{14}$. Por lo que se refiere a Garci Alfonso de Triguero, tanto su posición como alcalde de la reina María, como su actuación como pesquisidor y juez de salario al servicio de la corona se documentan sin dificultad en los primeros años del rey don Pedro ${ }^{15}$. Como vemos, la apreciación del contexto en que se mueven estos funcionarios del entorno de la corte, al ampliar el foco de la atención que dirigimos sobre ellos, permite documentarlos sin equívoco como figuras de la época central del siglo XIV, con protagonismo bajo el rey don Pedro, y de esta forma ayuda a descartar la teoría de que estas ordenanzas puedan datarse en el tiempo de los primeros Trastámaras.

los quatro dados por los pecheros, seyendos [sic] llamados por los dichos Tel Ferrandez e Garçia Alonso, alcaldes, para les mostrar los hordenamientos que fueron fechos por ellos e por los que han de aver fazienda del dicho conçejo, e por Benito Perez, alcalde, e fueron puestos en renta e arrendadas, e fueron [tachado: «des»] fechos por carta de la Reyna a pedimiento de los pecheros, los quales hordenamientos fueron leydos delante todos estos sobre dichos, e preguntaronles que les dixesen en que eran agraviados, que los enmendasen; e por todos los sobre dichos fueron enmendados los dichos hordenamientos en esta manera que se sygue; e fue acordado por todos que los pusyesen en renta por quel dicho conçejo oviese pro»: El Escorial, ms. X-II-19, fol. 129v.

13 SITGES, J. B., Las mujeres del rey don Pedro I de Castilla, Madrid, 1910, p. 54.

14 El 8 de octubre de 1352, Pedro I ratificó sus acuerdos con Pedro IV y delegó en Tel Fernández de Toledo tomar el juramento sobre ello del monarca aragonés (DÍAZ MARTÍN, Op. Cit., doc. no. 761, t. III, p. 101); el 13 de diciembre de 1360, Pedro I ordenó a las justicias del arzobispado de Toledo que procedieran a vender los bienes confiscados de Samuel el Leví, y que entregaran lo que se obtuviera, precisamente a Tel Fernández, quien aparece aquí como hombre de confianza del rey (Idem, doc. no. 1125, t. IV, p. 44); antes del 13 de abril de 1366, Tel Fernández, a quien se identifica como «alcalde mayor de Toledo», recibe de Pedro I un encargo sobre cierto rosario que fuera del arzobispo D. Vasco (Idem, doc. no. 1340, t. IV, p. 240); el 26 de mayo de 1367, Tel Fernández, nuevamente identificado como «alcalde mayor de Toledo» y «recaudador de la diócesis», recibe del rey el cargo de recaudador de las rentas reales en la ciudad (Idem, doc. n.ำ1379, t. IV, p. 263).

15 El 10 de agosto de 1350, Pedro I encomendó a Garci Alfonso de Triguero, identificado como «alcalde de la reina María», que viajara a Baeza como pesquisidor (DÍAZ MARTíN, Op. Cit., doc. no. 50, t. I, p. 99); el mismo día, el monarca impuso al concejo de Baeza la paga del salario de este enviado suyo (Idem, doc. no. 51, t. I, p. 99); el 9 de septiembre del mismo año, el rey, accediendo a la petición de dicho concejo, puso fin a la misión de Garci Alfonso (Idem, doc. no. 55, t. I, p. 102); y el 16 de noviembre el rey lo envía en nueva misión a hacer pesquisa en la ciudad de León (Idem, doc. no. 70, t. I, pp. 112-114: en este documento se hace referencia a él como «Garçia Alfonso de Triguero, de Toro, alcalde de la Reyna mi madre» - p. 112-). 


\section{LOS PECHA, GUADALAJARA..., Y LA REINA DOÑA MARÍA}

Otro interesante cauce de aproximación a la actuación de la reina María de Portugal al frente del señorío de Guadalajara viene dado por el arraigo del linaje de los Pecha en dicha villa y su entorno. El profesor Moxó dedicó en su día un estudio ejemplar al ascenso de esta familia de procedencia italiana en el servicio cortesano, político y administrativo, durante el reinado de Alfonso XI, a quien Fernán Rodríguez Pecha sirvió eficazmente, desde su oficio de camarero regio, como intendente y hombre de confianza, afecto al círculo íntimo o equipo de gobierno del rey ${ }^{16}$. Fernán Rodríguez Pecha figura como camarero mayor de Alfonso XI de 1326 a 1345; desde 1335, ejerció asimismo el oficio de camarero mayor del infante don Pedro (el futuro rey) ${ }^{17}$; de 1326 a 1344, cuidó en el seno de la cancillería regia de la elaboración de una serie de privilegios rodados de los que figura directamente como responsable ${ }^{18}$; de su pertenencia al más selecto círculo de los colaboradores de confianza de Alfonso XI da idea el hecho de que se contara entre los que fueron armados caballeros por el mismo rey en 1330, en Burgos, con motivo de la coronación del monarca ${ }^{19}$.

Aunque consta su arraigo en tierras de Guadalajara desde fecha anterior (al parecer, desde 1313, cuando adquirió unas viñas en su término, según se sigue de las cláusulas de la fundación de su mayorazgo principal ${ }^{20}$ ), lo cierto es que su gran vinculación con esta villa del Henares se ha venido atribuyendo tradicionalmente a su casamiento con doña Elvira Martínez, quien tenía un hermano (Diego) en la cámara regia y ella misma ejercía el oficio de camarera mayor de la reina doña María $^{21}$. Se acepta que su matrimonio con Elvira fue el motivo principal de que Fernán Rodríguez se instalara en Guadalajara, donde consta como vecino desde 1330 (supone Moxó que desde esa fecha Fernán Rodríguez se distanció progresivamente de sus responsabilidades en la corte, y que algún lugarteniente suyo se ocupó en adelante de preparar en su nombre los privilegios reales) ${ }^{22}$. A partir de este momento, el rey ayudó a Fernán Rodríguez y su esposa Elvira Martínez a aposentarse cómodamente en Guadalajara, donde les hizo objeto de diversas donaciones de dineros, un solar situado junto al alcázar real de la población donde edificar su casa solariega, heredades cercanas (el «Prado de la Puente» en Guadalajara) o radicadas en la comarca alcarreña (una heredad en término de Hita), y

\footnotetext{
16 MOXÓ, Salvador de, «El auge de la burocracia castellana en la corte de Alfonso XI. El camarero Fernán Rodríguez y su hijo el tesorero Pedro Fernández Pecha», en el Homenaje a don Agustín Millares Carlo, Gran Canaria, 1975, t. II, pp. 11-42.

17 MOXÓ, Op. Cit., p. 13. Como camarero mayor de Alfonso XI y de su hijo el infante Pedro aparece caracterizado, por ejemplo, en un documento dado en Valladolid, el 7 de enero de 1336: VEAS ARTESEROS, Op. Cit., doc. no. 300, p. 345.

18 MOXÓ, Op. Cit., p. 15.

19 MOXÓ, Op. Cit., p. 13.

20 MOXÓ, Op. Cit., p. 22.

21 MOXÓ, Op. Cit., p. 14, nota 8, y p. 18, nota 17.

22 MOXÓ, Op. Cit., pp. 14 y 22.
} 
variadas rentas (algunas situadas en Guadalajara, sobre los molinos del Henares) $)^{23}$.

Curiosamente, tanto Moxó como otros autores aceptan, como queda dicho, que el casamiento de Fernán Rodríguez con Elvira Martínez fue el motivo principal de que el linaje de los Pecha acabara arraigando en Guadalajara, donde acabó convirtiéndose en una de las familias más acreditadas de su patriciado urbano; pero no consta especialmente que Elvira Martínez estuviera ella misma arraigada en la villa, toda vez que se desconoce cuál haya sido el origen de su patrimonio familiar $^{24}$. Naturalmente, la solución de este pequeño enigma se aclara atendiendo a la circunstancia de que la reina María de Portugal, a cuyo servicio estaba estrechamente ligada Elvira Martínez como su camarera mayor, fue señora de Guadalajara: puede muy bien haber sido que, en último término, la causa de la instalación del matrimonio Pecha en Guadalajara haya respondido a la necesidad de ocuparse de los intereses señoriales de la reina doña María en esta su villa, y muy concretamente, que durante el tiempo que Fernán Rodríguez y su esposa Elvira residieron en Guadalajara, tuvieran a su cargo la intendencia del alcázar regio, a uno de cuyos costados, sobre un solar donado por la corona, hicieron edificar su propia morada principal y casa solariega. En esta hipótesis vendrían a concordar, tanto el motivo de la instalación del matrimonio Pecha en Guadalajara, donde Fernán Rodríguez consta como vecino desde 1330, como la circunstancia de que sus casas mayores se edificaran junto al mismo alcázar, pegadas a sus muros, de espaldas a la muralla de la villa, y dando a la gran plaza principal presidida por el alcázar, a la que también daba la iglesia de Santiago, a cuya parroquia pertenecieron Fernán Rodríguez y Elvira, y en la que fundaron una capilla propia (de la Trinidad) donde el primero se haría más tarde enterrar ${ }^{25}$.

Otro detalle permite ligar nuevamente la instalación de los Pecha en tierras de Guadalajara con la actuación de la reina doña María al frente de su señorío. Concierne, específicamente, a la donación que doña María les hizo de la aldea de Atanzón, de la que consta que previamente a su integración en el patrimonio familiar de los Pecha, había sido aldea de la villa de Guadalajara ${ }^{26}$. En sus Aumentos

${ }^{23}$ Constan todas estas donaciones por el tenor de la escritura de fundación de mayorazgo que los esposos otorgaron, para después de sus días, la cual describe puntualmente y publica MOXÓ, Op. Cit., pp. 17-18, y 26-33.

24 MOXÓ, Op. Cit., p. 18, nota 17. Por su testamento, de 1374 -Archivo Histórico Nacional, Madrid $(\mathrm{AHN})$, sección de Clero, legajo 2151 y libro 4378, fols. 131-137-, sabemos que el padre de Elvira había poseído algunos bienes en Guadalajara, pero no consta que los tuviera con anterioridad al momento en que su hija se instaló en la villa. Considerando el problema, Josemaría REVUELTA SOMALO concluye que la mención en su testamento a bienes en la villa legados por su padre no basta «para probar que Elvira naciera en Guadalajara»: Los jerónimos. Una orden religiosa nacida en Guadalajara, Guadalajara, 1982, p. 93.

${ }_{25}$ MOXÓ, Op. Cit., pp. 18, 22. Elvira Martínez se enterró mucho más tarde en la iglesia del convento guadalajareño de San Antolín, con el que mantuvo una estrecha relación en su viudez: REVUELTA SOMALO, Op. Cit., pp. 92-93.

26 En la escritura de ampliación de su mayorazgo, Fernán Rodríguez menciona dicha aldea y su procedencia: «la mi aldea del Atanzon que es en la Alcarria, termino que fue de Guadalajara segun que me- 
a las Relaciones topográficas, el cronista provincial guadalajareño Juan Catalina García comenta la escritura de ampliación del mayorazgo de Fernán Rodríguez y se interroga por la manera como la aldea de Atanzón salió de la jurisdicción de la villa de Guadalajara, a la que consta que había pertenecido ${ }^{27}$. Siguiendo a Catalina, Moxó cita un privilegio en que doña María concedió a los de Atanzón, en 1329, derechos de pasto y aprovechamiento de leña en término de Guadalajara (del que en esa fecha, por lo tanto, la aldea citada ya no formaba parte) ${ }^{28}$. Moxó deduce acertadamente que Atanzón formó parte del patrimonio señorial de doña María, pero añade que antes la aldea hubo de apartarse de la jurisdicción y término de Guadalajara y entregarse a dicha reina («debió pertenecer a la jurisdicción de Guadalajara como aldea suya hasta que se entregó a aquella Reina, pasando al patrimonio señorial de ésta» ${ }^{29}$ ).

Esta última suposición no es necesaria si se comprende que María era señora de Guadalajara, y por serlo, también de su término, en el que Atanzón se halló comprendida como aldea hasta que la misma reina, su señora, la cedió a Fernán Rodríguez Pecha, en fecha desconocida. Esto es, que por no cobrar conciencia clara del hecho de que María de Portugal era señora de Guadalajara, Moxó no alcanzó a ver que Atanzón no tuvo necesidad de apartarse de Guadalajara para llegar a pertenecer al señorío de doña María: ya formaba parte de él, junto a las restantes aldeas de Guadalajara, y de este señorío de la reina sólo salió para entrar en el de Fernán Rodríguez. Como se aprecia, simplemente el tener en cuenta la presencia y la actuación de la reina María al frente del señorío de Guadalajara arroja nueva luz sobre algunos puntos hasta entonces insuficientemente aclarados.

Análogamente, sabemos que durante el tiempo que estuvo al frente del señorío, María de Portugal hizo objeto a los Pecha de otra interesante donación: a saber, el monte de Alcohete, situado entre Guadalajara y la vecina Lupiana (población esta última especialmente significativa con relación a los Pecha, que en ella emprenderían poco después la fundación de la casa madre de la orden jerónima): este término, entregado por la reina María a Alfonso Pérez Pecha, hijo de Fernán Rodríguez y obispo de Jaén desde 1359, se acabaría integrando en el patrimonio conventual de San Bartolomé de Lupiana, y su posesión sería más adelante confirmada por la consorte del primer Trastámara, la reina Juana Manue ${ }^{30}$. Naturalmente, de todo el asunto, lo que especialmente interesa a nuestro propósito es la

jor e mas complidamente la yo he por merced e donacion que mi señora la Reina doña Maria me fizo deIlo»: MOXÓ, Op. Cit., p. 34.

27 «Presumo que antes de esta fundación, hecha en 1340 [Moxó no se aventura a fecharla con tanta precisión], habían apartado la aldea de la jurisdicción de Guadalajara, porque claramente dice una de las cláusulas de la escritura al nombrar a Atanzón que fue aldea de dicha villa, cabeza de la tierra»: GARCÍA LÓPEZ, Juan Catalina, Relaciones topográficas de España. Relaciones de pueblos que pertenecen hoy a la provincia de Guadalajara, Memorial Histórico Español, t. 41, 1903, p. 224.

${ }_{28}$ MOXÓ, Op. Cit., p. 19.

29 Ibidem.

${ }_{30}$ Conocemos la anterior donación de Alcohete hecha por María de Portugal en beneficio de Alfonso Pérez Pecha, precisamente por esta confirmación de Juana Manuel, dada en Soria el 10 de junio de 1375: AHN, Clero, legajo 2159. 
posibilidad de verificar por otro camino la actuación de María de Portugal como señora de Guadalajara, pues fue como titular del señorío de esta villa que pudo disponer del monte de Alcohete, comprendido en su tierra, cuando se lo entregó primeramente a Alfonso Pérez.

Existe, por añadidura, al menos otro ejemplo de la actuación de doña María como señora de poblaciones comprendidas en la tierra de Guadalajara en la misma época. Se refiere, concretamente, a las relaciones entre el concejo de Ayllón y su antigua aldea de Tamajón, que fue separada por la reina de la jurisdicción de aquél para entregarla a Íñigo López de Orozco, a quien fue luego confirmada su posesión por el rey Pedro en $1365^{31}$. Posteriormente, el rey autorizó a los vecinos de Tamajón a que llevaran sus ganados a pacer en término de Ayllón, como antes de la segregación, mencionando el pleito que sobre esta cuestión mandó librar en su vida la anterior señora, su madre la reina doña María, cuya actuación al frente del señorío queda así suficientemente acreditada ${ }^{32}$. Naturalmente, María de Portugal era señora de Guadalajara, y por lo tanto de Ayllón, cuyo término se entendía comprendido en la tierra de Guadalajara, de la misma manera que fue también señora de Atanzón por serlo de Guadalajara.

\section{LA REINA MARÍA DE PORTUGAL COMO SEÑORA DE GUADALAJARA}

Como se puede apreciar, en los apartados anteriores del presente estudio hemos pasado revista a una relación de temas y noticias cuyo tratamiento histórico se aclara notablemente luego de tomar en cuenta la presencia de María de Portugal al frente del señorío de Guadalajara: así, tanto la correcta datación de aquella importante serie de ordenanzas municipales de la villa que hemos reseñado, como la razón del arraigo de los Pecha en el solar guadalajareño. Naturalmente, ello hace necesario basar sobre un sólido fundamento la titularidad y el ejercicio efectivo del señorío de Guadalajara por la reina María, tarea que intencionadamente hemos dejado para este apartado.

Que doña María fue señora de Guadalajara desde el mismo momento de sus esponsales con Alfonso XI de Castilla, celebrados en septiembre de 1328, es bien sabido desde la publicación de las capitulaciones matrimoniales, como recoge expresamente el padre Enrique Flórez en sus célebres Memorias de las Reynas Catholicas:

31 1365, mayo 30. Pedro I confirma a Íñigo López de Orozco el privilegio dado por la reina María, concediéndole la aldea de Tamajón, que había sido del concejo de Ayllón: DíAZ MARTíN, Op. Cit., doc. no. 1317 , t. IV, p. 213.

32 1366, abril 8, Toledo. Pedro I autoriza a los vecinos de Tamajón a que sus ganados pazcan en la sierra de Ayllón: DÍAZ MARTÍN, Op. Cit., doc. no. 1339, t. IV, pp. 237-240. Concretamente, reza: «Et por quanto la reyna donna Maria, mi madre que Dios perdone, encomiendo por su carta a Nicolas Peres, alcalle et alguasil que era y en Aellon a la sason, que librase el dicho pleito entre las dichas partes...», p. 238. 
Notas sobre María de Portugal, reina de Castilla, como señora de Guadalajara...

«Las arras que el Rey [Alfonso XI] dio a su muger fueron los alcázares, castillos y villas de Guadalajara, Talavera y Olmedo con todos sus términos, derechos, rentas, jurisdicciones y pertenencias, como expressa el ya citado instrumento de las capitulaciones» ${ }^{33}$.

Además de esta noticia, que se hace eco de los mismos términos en que dichas villas y plazas fueron entregadas a la reina con motivo de su casamiento con el monarca castellano, disponemos asimismo de otros testimonios inequívocos que prueban la actuación efectiva de doña María al frente del señorío de Guadalajara.

En primer lugar, podemos citar dos documentos suyos en los que concedió al convento de Santo Domingo el Real de Madrid, por motivo de piedad, sendas participaciones en las rentas que como señora de Guadalajara percibía anualmente en esta villa: el 29 de marzo de 1342 vinculó un millar de maravedíes procedente de estas rentas señoriales situadas en Guadalajara («en las mis rentas et derechos de Guadalfaiara»), encomendando velar por su pago "a los alcalles, et a los jurados, et al juez de Guadalfaiara»; poco más de una década más tarde, el 15 de octubre de 1353, la misma reina amplió dicha merced en quinientos maravedíes anuales suplementarios que el convento de Santo Domingo de Madrid habría de percibir en sus rentas señoriales de Guadalajara. Tanto el hecho de que doña María dispusiera como suyas de estas rentas señoriales de la villa del Henares, como el mandato expreso que da a sus autoridades locales para que garantizaran la entrega de las cantidades comprometidas al convento madrileño, atestiguan suficientemente el ejercicio de la función señorial por parte de la reina ${ }^{34}$.

Por otra parte, el análisis de la suscripción notarial de un importante convenio suscrito en 1352 entre el cabildo de clérigos de Guadalajara con los dos conventos mendicantes de la villa, de franciscanos y de clarisas, regulando diversas cuestiones relacionadas con servicios litúrgicos, usos procesionales y el reparto de derechos funerarios, acredita asimismo la presencia de la reina al frente del señorío de Guadalajara, pues el escribano del documento, Diego González, ejerce el oficio de la escribanía local en nombre de la reina, cuyo era el señorío (concretamente, la fórmula de suscripción comienza: «Et yo, el dicho Diego Gonçalez, escrivano publico sobre dicho del dicho logar Guadalafajara por la dicha sennora Reyna») $)^{35}$.

De esta suerte, tres documentos originales de la época nos permiten remachar sin mayor duda la titularidad y el ejercicio por María de Portugal del señorío de

33 FLÓREZ, Enrique, Memorias de las Reynas Catholicas, Madrid, 1761, t. II, p. 600.

34 AHN, Clero, carpeta 1359, docs. nos. 20 (9) y 20 (10), respective. Veáse su texto en los nos. 1 y 3 de nuestro Apéndice documental.

${ }_{35}$ AHN, Clero, carpeta 567, doc. no. 15. Publ. en: MARTíN PRIETO, Pablo, «Las relaciones del clero parroquial de Guadalajara con las órdenes mendicantes: el convenio de 1352», en Actas del VIII Encuentro de Historiadores del Valle del Henares, Alcalá de Henares, 2002, pp. 127-141 [140]. Veáse también su texto en el no. 2 de nuestro Apéndice documental. 
Guadalajara, pieza fundamental que dota de pleno sentido a los hechos analizados en las anteriores secciones del presente estudio ${ }^{36}$.

\section{CONCLUSIÓN}

Sencillamente se puede afirmar que el insuficiente reconocimiento por parte de la historiografía de la condición de María de Portugal como señora de Guadalajara desde su matrimonio con Alfonso XI hasta su extrañamiento de Castilla en 1356 ha dado lugar a alguna confusión en el registro e interpretación de ciertos hechos referidos a la época. La indudable postergación de que este miembro femenino de la familia real fue objeto durante el reinado de Alfonso XI en beneficio de la favorita del monarca doña Leonor de Guzmán, sólo en parte contrarrestada por la luz que sobre su actuación bajo el reinado de su hijo el rey Pedro arroja el cronista Ayala (quien dedica a doña María cierta atención), puede haber contribuido a obscurecer su figura histórica, y por lo mismo, haber coadyuvado a formar este olvido relativo en que la tuvieron cuantos autores se ocuparon de la historia de Guadalajara.

Tal vez otro motivo de esta parcial obliteración de su figura se relacione con la entronización de la nueva dinastía de los Trastámara y el consiguiente efecto de anulación de la obra del rey Pedro, de cuya época al frente de la Corona de Castilla se quiso en cierta manera hacer borrón y cuenta nueva. Quizás la omisión del papel que María de Portugal desempeñó al frente del señorío de Guadalajara, en relación con materia tan relevante como la ordenación y promulgación de una notable serie de ordenanzas locales, tenga que ver precisamente con la programada damnatio memoriae de cuanto tuvo relación con el reinado de Pedro I, y un eco de esta opción haya sobrevivido hasta influir sobre la obra del cronista Layna Serrano, a quien cierto prejuicio, propio o inducido, impedía reconocer la correcta datación de aquellas ordenanzas (por lo demás suficientemente clara). No debe olvidarse, a este respecto, que aunque dichas ordenanzas datan de la época de Alfonso XI, cuyo reinado carecía de cualquier sombra de polémica para los ideólogos del nuevo poder Trastámara, el recuerdo de la misma figura de la reina María, a quien el cronista Ayala $^{37}$ señala de manera inequívoca como inductora de la muerte de Leonor de Guzmán, podía ciertamente causar cierta incomodidad a los primeros titulares de la nueva dinastía.

\footnotetext{
36 Al respecto, cabe recordar la frecuencia con que, en el periodo estudiado, se producían estas concesiones de señoríos a reinas consortes e infantas solteras, como medio —relativamente seguro para la integridad del realengo- de elevar su estado y contribuir a financiar sus gastos: MOXÓ, Salvador de, Los antiguos señoríos de Toledo, Toledo, 1973, p. 32. Concretamente, de Alfonso XI se ha llegado a afirmar que fue tan pródigo en este tipo de concesiones que tenían por beneficiarios a miembros de su familia, como reacio en materia de donaciones a miembros de la nobleza: BECEIRO PITA, Isabel, «Los dominios de la familia real castellana (1250-1350)", en Génesis medieval del Estado moderno: Castilla y Navarra (1250-1370), Valladolid, 1987, p. 80.

37 LÓPEZ DE AYALA, Pero, Crónica del Rey don Pedro, año 1351, capítulo 3.
} 
En cualquier caso, no ya el descubrir que doña María fue señora de Guadalajara (por cuanto ello era o podía ser conocido desde tiempo atrás, cuanto menos desde la difusión de la famosa obra del padre Enrique Flórez), sino el volver a poner este hecho paladinamente en el centro del tapete, contribuye a aclarar otros pormenores de la época, como hemos visto en las páginas precedentes, al tiempo que afianza un resultado parcial indispensable para la reconstrucción de la nómina de quienes en tiempos medievales ostentaron y ejercieron el señorío de aquella villa.

\section{APÉNDICE DOCUMENTAL}

1342, marzo 29, Valladolid.

La reina María de Portugal concede al monasterio de Santo Domingo el Real de Madrid mil maravedíes anuales en sus rentas de Guadalajara.

AHN, Clero, carp. 1359, doc. no. 20 (9).

Donna Maria, por la graçia de Dios Reyna de Castiella et de Leon, por fazer bien et merçed alla priora et al convento de las duennas del monesterio de Santo Domingo de Madrit, et por que sean tenudas de rogar a Dios por la vida et la salud del Rey mio sennor, et mia, et del Infante don Pedro, mio fijo, tengo por bien de les poner que tengan de mi, para de cada anno, desde primero dia de abril primero que viene de la era desta carta en adelante, en quanto yo tovie por bien et la mi merçed fuere, mille maravedis en las mis rentas et derechos de Guadalfaiara. Et mando, por esta mi carta, a qual quier o a quales quier que ovieren de coger et de recabdar en renta o en fialdat, o en otra manera qual quier, las mis rentas et derechos de Guadalfaiara, desde primero dia de abril primero que viene en adelante, de cada anno, que recudan et fagan recudir con los dichos mille maravedis al que los oviere de aver por la dicha priora et convento, por los terçios del anno, en cada raçon lo que y montare, bien e conplidamente. Et non los demanden contra mi carta mandadera primero de cada anno, nin por cada terçio, por esta razon; ca con el traslado desta mi carta signado de escrivano publico, e con carta de pago de la dicha priora et convento, o del que los oviere de recabdar por ellas, ge los mandare resçebir en cuenta.

Et non fagan ende al, so pena de la mi merçed; si non, mando a los alcalles, et a los jurados, et al juez de Guadalfaiara, que agora son o seran daqui adelante, 0 a qual quier o a quales quier dellos que esta mi carta vieren, que ge lo fagan assi fazer et conplir, en guisa que se cunpla esto que yo mando; et non fagan ende al, so pena de çien maravedis de la moneda nueva a cada uno. Et desto les mande dar esta mi carta seellada con mio seello de çera colgado. La carta leyda, dagela. 
Dada en Valladolit, veynte et nueve dias de março, era de mille et trezientos et ochienta annos.

Yo, Bartolome Sanchez, la fiz escrevir por mandado de la Reyna.

1352, agosto 19, Guadalajara.

Convenio entre el cabildo de clérigos de Guadalajara, y los conventos de San Francisco y de Santa Clara de la misma villa, para regular aspectos relacionados con la prestación de servicios funerarios y la práctica de la predicación.

AHN, Clero, carp. 567, doc. no. 15.

En el nonbre de Dios, et de Santa Maria, et de toda la corte çelestial, sepan quantos esta carta de conpusiçion et de abenençia vieren commo yo, Nunno Ruyz de Alcala, arçipreste de Guadalfajara; et yo, Garçia Perez, clerigo en la yglesia de Santiago; et yo, Sancho Perez, et yo, Lope Gonçalez, et yo, Nunno Garçia, et yo, Johan Martinez, clerigos en la yglesia de Santa Maria; et yo, Domingo Ferrandez, et yo, Alvar Ferrandez, et yo, Benito Ferrandez, clerigos en la yglesia de Sant Nicolas; et yo, Domingo Martinez, et yo, Lazaro Martinez, clerigos en la yglesia de Sant Gil; et yo, Pero Martinez, clerigo en la eglesia de Sant Miguel, vezinos del dicho lugar, por nos et en nonbre del cabildo de los clerigos del dicho logar, asi de los que agora son commo de los que seran daqui adelante; et yo, fray Garçia de Usanos, guardian del monesterio de los frayres de San Françisco del dicho logar, et yo, fray Johan Diaz de Valladolit, lector, et yo, fray Alfonso de Guadalfajara, sacristan, et yo, fray Diego de Madrit, maestro de logica, et yo, fray Johan de Yliestas, frayreres [sic] que somos del convento del dicho monesterio, por nos et en nonbre de los frayres del dicho convento que agora y son et seran daqui adelante en el dicho monesterio; et nos, donna Leonor Ruyz, por la graçia de Dios abadesa del convento de las duennas del monesterio de Santa Clara del dicho logar, et yo, Johana Remont, et yo, Maria Garçia, et yo, Sancha Garçia, et yo, Teresa Ruyz, et yo, Ynes Blasquez, et yo, Catalina Ferrandez, et yo, Clara Ferrandez, et yo, Clara Gonçalez, duennas que somos en el dicho monesterio, por nos et en nonbre del dicho convento de las dichas duennas que agora en el son et seran daqui adelante, non engannosas nin costrennidas, mas con liçençia et abtoridat et conssentimiento que nos dio don Gonçalo, por la graçia de Dios arçobispo de Toledo, et otrosi con liçençia et autoridat et mandamiento que nos dio et otorgo fray Pedro de Castro, ministro de los frayres menores en la provinçia de Castilla; estando presente a esto todas tres las dichas partes, otorgamos et conosçemos que fazemos conposiçion et abenençia segunt que daqui adelante dira:

Primera mente, que quando algun clerigo de aqui de Guadalfajara finare, que seamos tenudos, nos los dichos frayres, et sean tenudos de yr, ante noche, a hon- 
rrar el cuerpo et cantar la vigilia de muertos; et otro dia dar misa del enterramiento, la qual misa que la diga un frayre, et entierre el cuerpo et predique. Et eso mesmo, quando algun frayre muriere, que nos los dichos clerigos, que seamos et sean tenudos de yr, ante noche, a honrrar el cuerpo et cantar la vigilia de muertos, et otro dia dar misa de requiem, la qual diga un clerigo, et entierre el cuerpo. Otrossi, quando finare algun perrochiano de los dichos clerigos, et se mandare enterrar con los frayres, que sea guardada la costunbre que fasta agora fue guardada, senalada mente que tangan las canpanas en las perrochias de la villa ante noche, et otro dia, mientra levaren el cuerpo a San Françisco, et otrosi que tangan en la eglesia do fuer perrochiano, mientre levaren el cuerpo a San Françisco; et entonçe, que dos clerigos, o uno con el sacristan, lieven la cruz fata la puerta de la villa, a do an de recodir los frayres con su cruz, et el preste, et el diacono, et el sodiacono si fuer mester, revestidos; et del pan et de la otra ofrenda que y fuer aquel dia, que non den mas de la quarta parte.

Otrosi, que el dicho arçipreste et clerigos non conssientan non conssientan [sic] que prediquen en sus eglesias qual quier religioso de otra religion sin liçençia et consentimiento del guardian o del vicario que fuer al tienpo en el dicho monesterio de San Françisco.

En lo seguidero, lo que pertenesçe a la conpusiçion de nos, los dichos clerigos, et de nos, las dichas duennas del dicho monesterio de Santa Clara, avenymos en esta manera que daqui adelante dira:

Lo primero, que quando algun perrochiano de la villa finare et se mandare enterrar en el dicho monesterio de Santa Clara, que los dichos clerigos que sean tenudos de yr con su cruz, vestidos de sobrepellizes, a la dicha eglesia de Santa Clara, dando les lo que es acostunbrado: los ofiçios doblados; et si quisieren que alguno de los dichos clerigos diga la misa et entierre el cuerpo, que los dichos clerigos et la dicha abadesa et duennas non ge lo podamos nin puedan enbargar, pero que del pan et de toda la otra offrenda que aquel dia y vinieren, que non lieven los dichos clerigos mas de la quarta parte.

Otrosi, nos los dichos arçipreste et clerigos, en nonbre del dicho cabildo, otorgamos et conosçemos que somos pagados et entregados de toda quanta parte que aviemos de aver de los cuerpos que son enterrados en el dicho monesterio de Santa Clara fata este dia que esta carta es fecha et otorgada, pero que dos yuntas de heredat de bueyes que son Torrela, aldea deste dicho lugar, et seysçientos maravedis en dineros para reparamiento dellas, que Alffonso Ferrandez, alcayad, mando a las dichas duennas, otorgamos nos las dichas abadesa et duennas et arçipreste et clerigos, que finquen en esaminaçion et determinaçion de letrados que lo libren, si dixieren que avemos de aver nos los dichos arçipreste et clerigos la quarta parte dello, por quanto a los enterramientos que deste dia en adelante an de benir de los perrochianos de nos los dichos clerigos al dicho monesterio de Santa Clara, et ordenamos et establesçemos et abiniemos nos para sienpre, salvo ende si la yglesia de Roma mandase o declarase otra cosa de nuevo, o fiziere graçia so- 
brello, que las dichas abadesa o su vicaria et duennas non sean tenudas de dar parte ninguna a los dichos clerigos de lo quel finado les mandare para los ornamentos et conposturas de la yglesia o de su sepoltura, asi commo son pannos et ymagenes, nin de lo que mandase para la fabrica nin para la luminaria, nin para aniversario nin septanario nin bentenario nin treyntanario, nin de quales quier cosas general mente que les fuere mandadas para honrra et serviçio perdurable de Dios, asi commo son perpetuales et calizes o libros et bestimentas, salvo ende si fuese fecha a sabiendas alguna induçion o enganno por que los dichos clerigos fuesen privados de su derecho. Et asi finca declarado entre nos las dichas partes, que toda cosa que viniere con el cuerpo sobre el lecho o sobre el ataud, asi commo son pannos de oro, o quales quier otros, et de todas ofrendas et oblaçiones que fueren fechas el dia del enterramiento general mente, de qual quier limosna que les fuer mandadas por yntençion et razon de sepoltura, que las nos las dichas abadesa et duennas seamos tenudas et sean de dar a los dichos clerigos su quarta parte a buena fe, sin mal enganno.

Otrosi establesçemos que quando nos los dichos clerigos fizieremos o fizieren proçesiones, que seamos et sean tenudos de entrar en la eglesia de Santa Clara con las cruzes en manera convenible, commo fazen en otras yglesias; et que otro dia de Santa Cruz de mayo, en la proçesion que fazemos, que entremos en la dicha yglesia de Santa Clara.

Et nos, los dichos guardian et freyres, por razon que vos los dichos clerigos otorgastes en esta carta que non conssentiessedes que predicasen en vuestras yglesias qual quier religioso de otra religion sin liçençia et conssentimiento del guardian o del vicario que fuese al tienpo en el dicho monesterio de San Françisco, otorgamos que estemos et esten aperçebidos para predicar sin deffecto quando nos fuer o les fuer encomendado.

Et por que todo esto que sobre dicho es sea mejor guardado et conplido, nos, los dichos arçipreste et clerigos, et guardian et frayres, et abadesa et duennas, todas estas tres partes sobre dichas, otorgamos et conosçemos et obligamos nos resçibiendo pena sobre nos o qual quier de nos las dichas partes que non guardare et quebrantare esta dicha conpusiçion, en toda ella o en parte della, que seamos et sean tenudos de pagar luego de llano, sin otro juyzio, por cada vez et por cada articulo que lo quebrantaremos, çient maravedis desta moneda usual que fazen diez dineros el maravedi, a la otra parte querellosa. Et para guardar et conplir todo quanto es contenido en esta sobre dicha carta de abenençia et conpusiçion, toda en la manera que dicha es, todas las tres partes sobre dichas obligamos todos nuestros bienes muebles et rayzes, espirituales et tenporales, et fazemos estipulaçion dende ante Diego Gonçalez, escrivano publico de Guadalfajara, que esta presente, a buena fe, sin mal enganno, de nunca yr contra ello en tienpo del mundo; et por mayor firmeza rogamos al dicho honrrado padre sennor don Gonçalo, arçobispo de Toledo, que toviese por bien de mandar poner en esta carta su seIlo pendiente: otrosi rogamos al dicho fray Pedro, ministro, que pusiese en ella el 
sello de su ofiçio, et cada una de nos las partes, los nuestros; et otrosi rogamos al dicho escrivano que fiziese ende tres cartas publicas, o mas, en una tenor, por que cada una de nos las partes toviese la suya, firmes et valederas, por que cada una dellas que paresçiere que vala et faga fe asi commo si todas tres paresçieren.

Et yo, el dicho fray Pedro, ministro, otorgo et conosco que di la dicha liçençia et autoridat et mandamiento a las dichas abadesa et duennas, para otorgar esta carta segunt que en ella se contiene. Fecha et otorgada esta carta en Guadalfajara, en la yglesia del monesterio de Santa Clara, a la grada, diez et nueve dias de agosto, era de mill et trezientos et noventa annos. Testigos que a esto fueron presentes, espeçial mente rogados: Sancho Miguel, et Domingo Ferrandez, capellanes; et Ruy Ferrandez de Belnis, canonigo de Palençia; et fray Marcho de Almaçan, conpannon del dicho ministro; et Anton Diaz, escrivano; et fray Marcho, et Johan Martinez, capellanes del dicho monesterio de Santa Clara. Ay escripto sobre raydo ende en tres logares, o dize «duennas»; et escripto entre renglones, o dize «nos», et non le enpesca. Et yo, el dicho Diego Gonçalez, escrivano publico sobre dicho del dicho logar Guadalafajara por la dicha sennora Reyna, fuy presente a todo lo sobre dicho con los dichos testigos, et por ruego et otorgamiento de los dichos arçipreste et clerigos, et guardian et frayes, et menistro et abadesa et duennas, escrevi esta carta para el monesterio de Santa Clara, et so ende testigo, et en testimonio de verdat fiz aqui este mio sig-[SIGNO]-no.

1353, octubre 15, Ciudad Real.

La reina María de Portugal concede al monasterio de Santo Domingo el Real de Madrid quinientos maravedíes anuales en sus rentas de Guadalajara.

AHN, Clero, carp. 1359, doc. no. 20 (10).

Sepan quantos esta carta vieren commo yo, donna Maria, por la graçia de Dios Reyna de Castilla et de Leon, por fazer bien et merçed a la priora et convento de las duennas de Santo Domingo de Maydrit, pongo les que tengan de mi, en las mis rentas et derechos de Guadalfaiara, desde primero dia de enero primero que vienga, que sera en la era de mille et trescientos et noventa et dos annos, en adelante, en quanto yo toviere por bien, la mi merçed fue quinientos maravedis cada anno, demas de los mille maravedis que ya tienen de mi de cada anno, en guisa que ayan mille et quinientos maravedis cada anno; los quales quinientos maravedis tengo por bien de les poner, segund dicho es, por quanto sean tenudas de rogar a Dios por el anima del Rey don Alfonso mi sennor, que Dios perdone, et por la vida et salud del Rey mio fijo, et mia. Et sobresto mando por esta mi carta a qual quier o a quales quier que cogieren o recabdaren en renta o el fialdat, o en otra manera qual quier, de las dichas rentas et derechos de Guadalfaiara, del dicho dia de enero en adelante de cada anno, den ende a la dicha priora et convento, o al 
que los oviere de aver por ellas, los dichos quinientos maravedis de cada anno, por los terçios del anno, en cada terçio lo que montaren, demas de los mille maravedis que de mi tienen, segund dicho es, en guisa que ayan cada anno mille et quinientos maravedis; et non les demanden otra carta mandadera para cada anno, nin para cada terçio, sobresta razon: ca con el traslado desta mi carta signado de escrivano publico, et con carta de pago de la dicha priora et convento, o de quien los oviere de aver por ellas, que ellos tomen en cada anno sobresta razon, que les mandare reçebir en cuenta.

Et non fagan ende al, so pena de la mi merçed; si non, mando a los alcalles et al alguazil de Guadalfaiara, o a qual quier o a quales quier dellos que esta mi carta vieren, que les prendan et tomen lo que les fallaren, et lo vendan luego, por que entreguen a la dicha priora et convento, o al que los oviere de aver por ellas, de los maravedis que ovieren de aver en cada uno de los dichos terçios, desque el terçio fuera conplido, et de la costa agravada que por esta razon fizieren a su culpa en los recabdar; et non fagan ende al, so la dicha pena de seysçientos maravedis desta moneda usual a cada uno. Et de commo esta mi carta les fuere mostrada, et los unos et los otros la cunplieren, mando, so la dicha pena, a qual quier escrivano publico que para esto fuere llamado, que de ende al que ge la mostrare testimonio signado con su signo, por que yo sepa en commo se cunple mio mandado.

Et desto les mande dar esta mi carta seellada con mio seello de çera colgado, dada en Villarreal, quinze dias de otubre, era de mille et trezientos et noventa et un annos.

Yo, Ruy Sanchez, la fiz escrevir por mandado de la Reyna. 